\title{
The assessment of the sawmill noise
}

\author{
P. D'Antonio, C. D'Antonio, C. Evangelista, V. Doddato \\ School of Agricultural Sciences, Forest and Environmental, University of Basilicata, Potenza, Italy
}

\begin{abstract}
Noise is a serious and widespread problem in many workplaces like in sawmill. The published data for the year 2010 about the total number of pathologies from work in Italia due to the noise, showed 5222 cases divided by sex, in fact for females there are instances in number of 221 while the male has a number of cases is equal to 4961 . The aim of this work was to detect the sound level caused by the use of the machineries in a sawmill. The measurements were carried out through an instrument known as noise level meter, equipped with a microphone and connected to a computer for data processing and analysis of variance to a factor in excel, and able to assess noise levels at any particular point in the mill. The machines were subjected in relief and with several different types of wood materials. Obviously, in our case a fundamental role takes the moisture of wood. The drying operation is intended to obtain that degree of humidity of the wood, generally it must be between 7 and 16\%, compatible with the type of glue used and, above all, appropriate to the target structures. The machines that have the highest sound pressure levels were trimmer and profiler, with values ranging between $85 \mathrm{~dB}(\mathrm{~A})$ and $110 \mathrm{~dB}(\mathrm{~A})$. Finally, it's possible conclude that the sound pressure level increases when the aspiration equipment is turned on, the noise of machinery decreases during the processing of wood and that, increasing the thickness, decreased the noise emitted by the machine.
\end{abstract}

\section{Introduction}

In Europe, around 50 million people are exposed to potentially hazardous levels of environmental noise, facing a risk of noise-induced hearing loss (NIHL). The loss in economic terms is substantial, at a minimum $0.2 \%$ of national net income. This equals about 400 billion

Correspondence: P. D’Antonio, School of Agricultural Sciences, Forest and Environmental, University of Basilicata, Via dell'Ateneo, 85100 Potenza, Italy.

Tel. +39.0971205471 - Fax: +39.0971205429 .

E-mail:dantonio@unibas.it

Key words: noise, sawmill, assessment, noise level meter, aspiration equipment.

(C) Copyright P. D'Antonio et al., 2013

Licensee PAGEPress, Italy

Journal of Agricultural Engineering 2013; XLIV(s2):e155

doi:10.4081/jae.2013.s2.e155

This article is distributed under the terms of the Creative Commons Attribution Noncommercial License (by-nc 3.0) which permits any noncommercial use, distribution, and reproduction in any medium, provided the original author(s) and source are credited.
Euros annually at European Community level (Rantanen et al, 2001). This includes direct and indirect costs related to production. The indirect costs do not include factors related to reduced quality of life. The quality of life includes: social isolation, increased unemployment and difficulties in family life due to communication difficulties related to hearing handicap.Noise-induced hearing loss (NIHL) is considered to be one of the most common occupational health hazards of any country. When NIHL is moderate to severe, it leads to speech distortion, reduced word discrimination, noise intolerance and tinnitus. Reduced oral communication is a social handicap. NIHL also reduces the perception of warning signals, environmental sounds and music. Consequently, NIHL may lead to social isolation, decreased worker productivity and morale, and an increase of job-related accidents. There are no global or European Community figures available for the prevalence of NIHL. Such figures, if they did exist, would provide a database that would allow focused control methods to reduce the risk at national level and work place level; and even at an individual level.The most common counter measure is the use of Hearing Protective Devices (HPDs). In most cases, this should be sufficient, since the noise levels are generally below $95 \mathrm{~dB}$ in $90 \%$ of the enterprises (Register on occupational exposures for physical and chemical agents, 1999). According to laboratory measurements (Comitee Europeen de Normalisation (CEN), parts 1 and 2, 1993), most earmuffs on the market can provide more than $20 \mathrm{~dB}$ attenuation against typical industrial noise.In field conditions, the situation is more complicated as people lack motivation to use HPDs (Berger et al., 1983; Foreshaw and Cruschley, 1981). Several researchers have shown that laboratory tests overestimate the attenuation of the protectors under investigation (Foreshaw and Cruzhley, 1981; Casali and Park, 1991; Merry et al., 1992). Furthermore, if the protectors are in poor condition, the attenuation tends to further deteriorate.In studies, the usage rate of hearing protectors has varied a great deal. Between 1953 and 1992 in the paper mill, HPDs were used 55\% of all work hours (Nieminen et al., 2000). Recently, higher usage rates have been found at the shipyards at $70 \%$ (Pekkarinen, 1987), and in forest work at 90\% (Pykko et al., 1989). A recent Italian lex (D.Lgs. 81/2008) fixes the daily noise exposure levels and peak sound pressure for exposure limit values and exposure action values:

a) Exposure limit values: $\mathrm{LEX}, 8 \mathrm{~h}=87 \mathrm{~dB}(\mathrm{~A})$ and $\mathrm{P}$ peak $=200 \mathrm{~Pa}$ respectively.

b) Upper exposure action values: $\mathrm{LEX}, 8 \mathrm{~h}=85 \mathrm{~dB}(\mathrm{~A})$ and P peak $=140$ $\mathrm{Pa}$ respectively.

c) Lower action values: $\mathrm{LEX}, 8 \mathrm{~h}=80 \mathrm{~dB}(\mathrm{~A})$ and P peak $=112$ Pa respectively.

When applying the exposure limit values, the determination of the worker's effective exposure shall take account of the attenuation provided by the individual HPDs worn by the worker. When the noise exposure level exceeds the lower exposure action values, the employer shall make HPDs available to workers, and HPDs shall be used where noise exposure levels match or exceed the upper action values. This study was intended to analyze the risk of noise in an Italian sawmill, relating to the use of the principal machineries for the timber transformation, taking in account the following factors: a) exposure to impulse noise, b) combined effects from the interactions between 
noise and the width of timber, c) analyzing the different type of the use of machineries and finally investigating about the use of HPDs in the sawmill.

\section{Materials and methods}

For each application you should check measurement technique and conditions in order to get valid and coherent results. The way of using the instrument has at least as much importance on result than device quality. During a normal working day, simultaneous measurements inside and outside the HPDs were conducted utilizing a miniature microphone and a portable 2-channel noise dose meter (Pekkarinen, 1987; Chang-Chun et al., 1989). These measurements were done with 21 paper mill workers in 1985, 28 shipyard workers in 1986, and 20 forest workers in 1989. Each measurement consisted of a 10-minute sampling period. According to recent Italian legislation, employers must provide appropriate HPDs for the workers, and use is mandatory. However, when evaluating the worker's right for compensation due to hearing loss, the use of HPDs is not taken into account. Since the workers receive no monetary gain for overestimating their usage rate, the likelihood of overestimation is diminished. The Sound Level Meter has been designed to meet the measurementrequirements for industrial safety offices and sound quality control invarious environments,

- $\quad$ Ranges from $35 \mathrm{~dB}$ to $130 \mathrm{~dB}$ at frequencies between $31.5 \mathrm{~Hz}$ and 8 $\mathrm{KHz}$;

- Display with $0.1 \mathrm{~dB}$ steps on a 4-digits LCD;

- With two weighting, A and C;

- Both AC and DC signals output is available from a singlestandard $3.5 \mathrm{~mm}$ coaxial socket suitable for a frequency analyzer,level recorder, FFT analyzer, graphic recorder, etc.

The relief of the noise on the holding object of the measurements was made on the machinery being used during the production cycle:

- Planer on four sides;

- Profiling;

- Splicer;

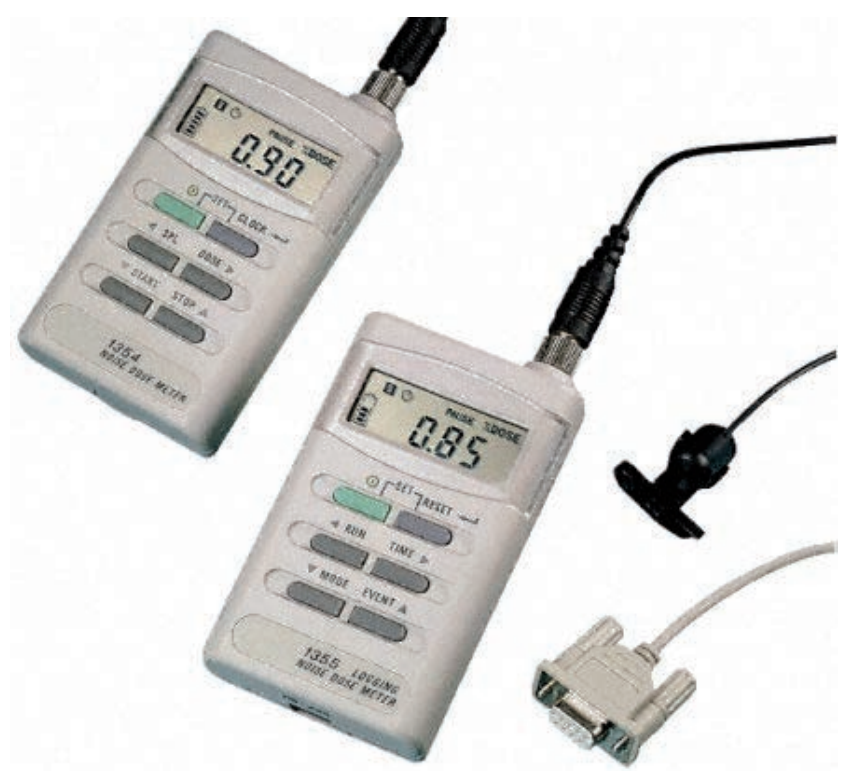

Figure1. Dosimeter.
- Trimmer - optimization.

It was not possible to carry out field surveys during a continuous production cycle, as it depended on the orders that came to the company, but data are collected when each piece of equipment was running, so it was possible to deduce the actual noise of the single machine without influences of other machinery on. On each machine were made more measures in such a way as to make a comparison between the different reliefs:

- An initial survey was carried out while the machine was switched on without aspiration and without the wood processing;

- A second measure with the suction on and without the wood being processed;

- A third and a fourth relief while they were working in wood of different thickness.

The wood species used in the trials was the silver Fir, aimed at different finished products such as beams and roof planks glued together with polystyrene which go to make up for insulated panels. All the machines in question were built according to CE standards and thus comply with the regulations in force and for each of them is available to the workers hearing protection.The data relating to the noisy machines were collected and analyzing thanks to the variance.

\section{Results}

The reliefs on the planer on four sides (Figure 2) have been set, as said earlier, comparing multiple variables in play. On this machine has not been possible to detect the sound pressure level while the machine was switched on without suction as it is an outbuilding that you can't turn off and then the analysis focused on data collected with different thicknesses.

The graph (Figure 3 ) will immediately notice that the that the sound pressure level for the planer falls below the $88 \mathrm{~dB}(\mathrm{~A})$ and no higher than $95 \mathrm{~dB}(\mathrm{~A})$, and this also shows that the most ups have occurred with the boards of fir thick white $160 \times 360 \mathrm{~mm}$, and less thick.

The values of sound pressure level registered onprofiling (Figure 4)

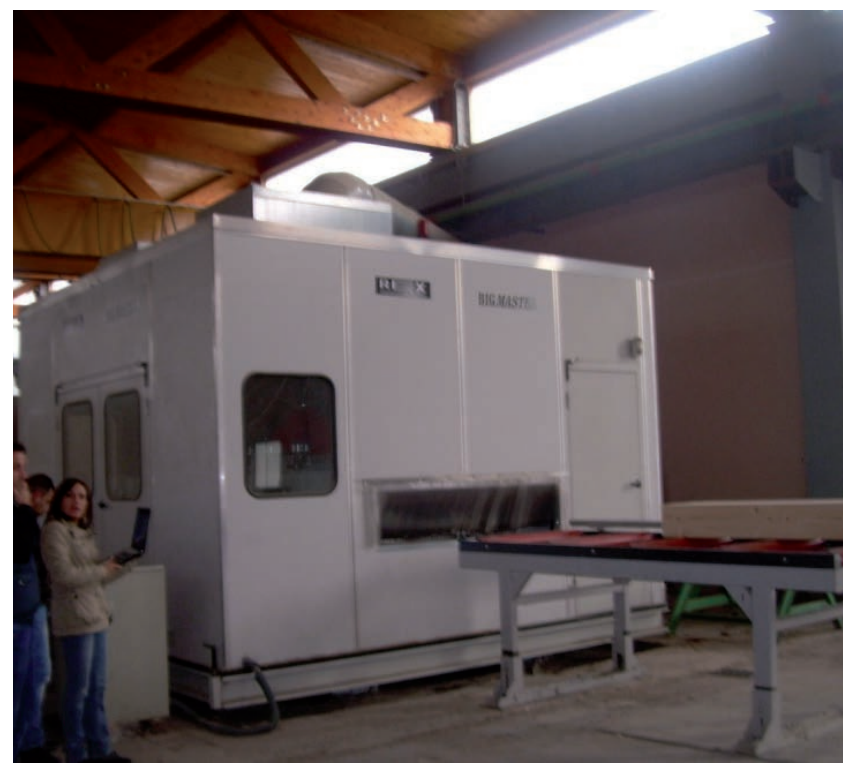

Figure 2. The reliefs on the planer on four sides. 
were higher than the values of the other machines. It is noted from the results of the graph (Figure 5) that the sound pressure level is around the threshold of $87 \mathrm{~dB}(\mathrm{~A})$. The operator wears headphones because, as can be seen, some value goes beyond the threshold of exposure and therefore the law provides for the use of PPE.

The valuesthat are registered on this machine while working the wood are much higher than previous measurements, even compared to measurements found on the planer on four sides, even for us who did relief, and so we were in close contact with the machinery for a short period of time the noise was loud and annoying, so that an operator has to work with the machine for several hours the long term risk is considerable.

In Figure 3, unlike the previous machine, the results showed that the values of the sound pressure level ranging between $90 \mathrm{~dB}(\mathrm{~A})$ and 110 $\mathrm{dB}(\mathrm{A})$ and are almost equal for both of the shims; while values increase compared to the observations made on the same machine without timber, with or without suction.The finished boards are glued with polystyrene and, as mentioned above are put in place to give rise to the panels to insulate roofs (Figure 6).

The optimizer, as showed in Table 1, it is not a very noisy machinery. The loudest noise is produced when the operator moves the plates from the plane of the trimmer to that of the splicing (Figure 7). Results show that the noise does not increase much, indeed, some values are decreased compared to the data detected while the machine is switched on without timber in processing.

In the graph (Figure 8), unlike the machinery above, the values of

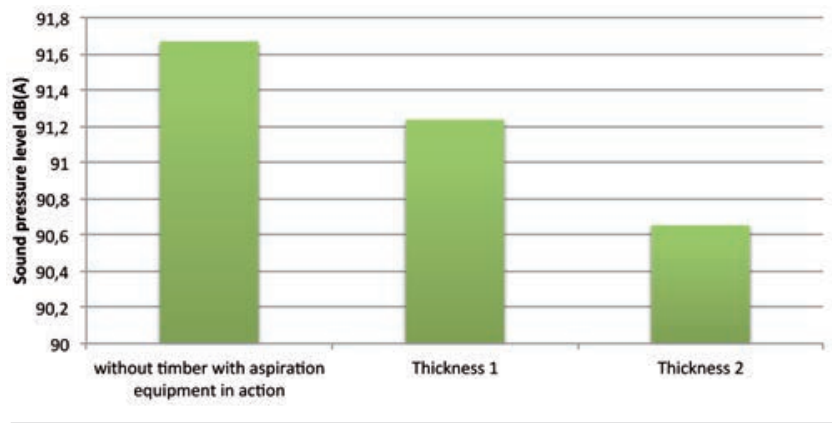

Figure 3. Graph of the sound pressure level of the planer.

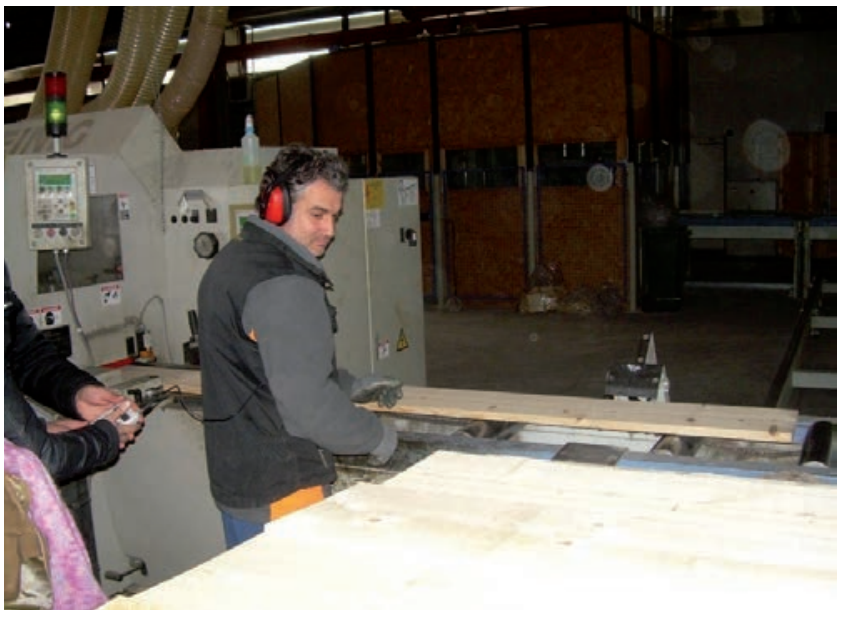

Figure 4. Relief of noise on profiling. the sound pressure level ranging between $80 \mathrm{~dB}(\mathrm{~A})$ and $100 \mathrm{~dB}(\mathrm{~A})$ and are almost equal for both of the shims.

This machine is equipped with a laser inside that goes to note where the table has been marked by the operator with a marker (in order to eliminate the defects) and cuts the table where there is no defect. The splicer, however, has the task of "splice", that combine two tables with a joint system (Figure 9). It is equipped with soundproofing system, consisting of a soundproof room built around the machine as it is very noisy.

In the graph (Figure 10) the values of the sound pressure level ranging between $80 \mathrm{~dB}(\mathrm{~A})$ and $100 \mathrm{~dB}(\mathrm{~A})$ and, you will immediately notice that the values for the thickness 2 are higher than those of the thickness 1 .

Ultimately, the values of the sound pressure level ranging between 75 $\mathrm{dB}(\mathrm{A})$ and $106 \mathrm{~dB}(\mathrm{~A})$ and the values for the values for the thickness 2 are higher than those of the thickness 1 . Furthermore, by comparing the averages of the values for the different machines, it notes that are scarcely different between a measurement and the other. The most noisy machinery is the profiling, even when the machine worked the timber with a different thickness. Below is the table (Table 1) that contains the data minimum, average and maximum values of different machinery analyzed with the use of the materials in different thickness.

The results showed that the profiling had sound pressure level higher than the other machines. As can be seen, the results do not fall below the $77 \mathrm{~dB}(\mathrm{~A})$ but below the threshold of $100 \mathrm{~dB}(\mathrm{~A})$. All this is not due to the timber used, or to its moisture, but just to the machinery itself

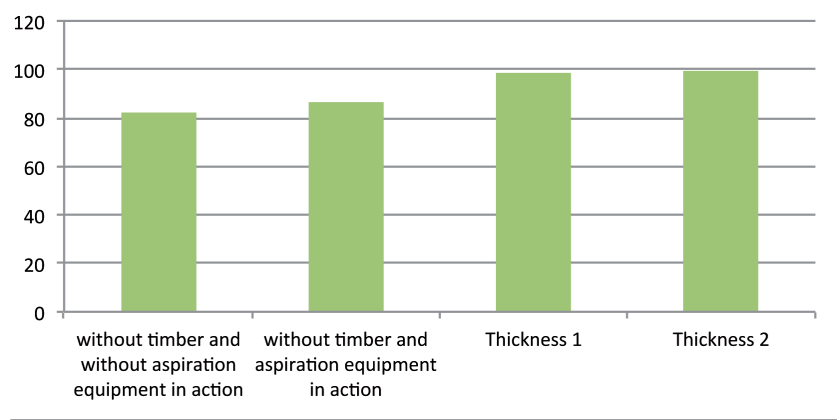

Figure 5. Graph of the sound pressure level of profiling/profiler.

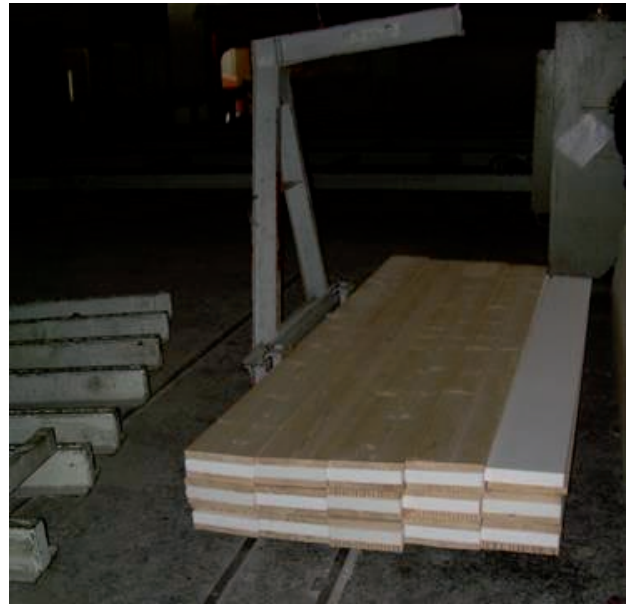

Figure 6. Panels to insulate. 
since, as can be seen from the findings, the noise is around values mentioned above even when it is switched on without that work. The other tested machineries with the highest sound pressure levels are the optimizer and the planer on 4 sides with values ranging between 85 $\mathrm{dB}(\mathrm{A})$ and $110 \mathrm{~dB}(\mathrm{~A})$, depending on the thickness of the timber and the use of aspiration equipment.

\section{Conclusions}

The machines used are all cutting edge and all built according to $\mathrm{CE}$ standards, but the results of our measurements showed, often, as the sound pressure level exceeds the limits allowed by law and it is precisely at this time that IPR play a role in the hearing of the operator in con- tact with the machine at that time. The Silver Fir is heavy (dry density of $410 \mathrm{~kg} / \mathrm{m} 3$ ), has good stability, retires on average and breaks, particularly well and dries well. Several factors can influence on increasing the sound pressure level emitted by the machine at the time of woodworking: moisture (whose increase causes a rise in ), cover the timber with paints and lacquers that increase the logarithmic decrement. Obviously, in our case a fundamental role takes on the moisture content of wood processed. The drying operation is intended to obtain that degree of humidity of the wood compatible with the type of glue used, and especially suited to the destination of the structures. Generally it has to be between 7 and 16\%. The results obtained are, as mentioned earlier, not much higher than the limits allowed by law, and considering the fact that the operator always wearing headphones at the time of the survey, we are in the norm. Perhaps the best way to reduce the noise of profiling is to construct, as in the case of the splicing, sound

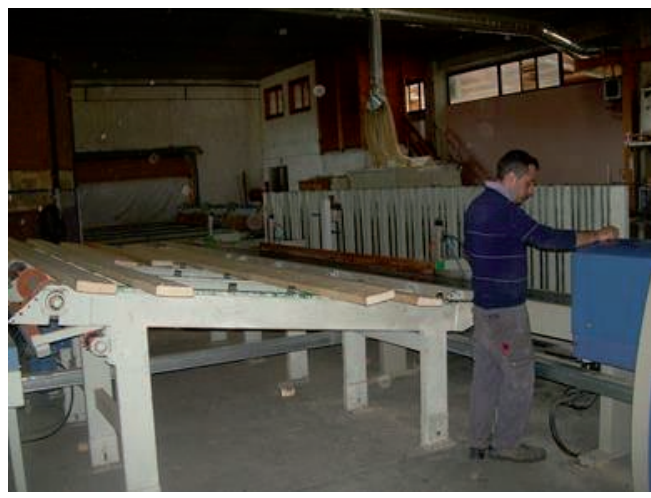

Figure 7. Plan Optimization transition from the splicer.

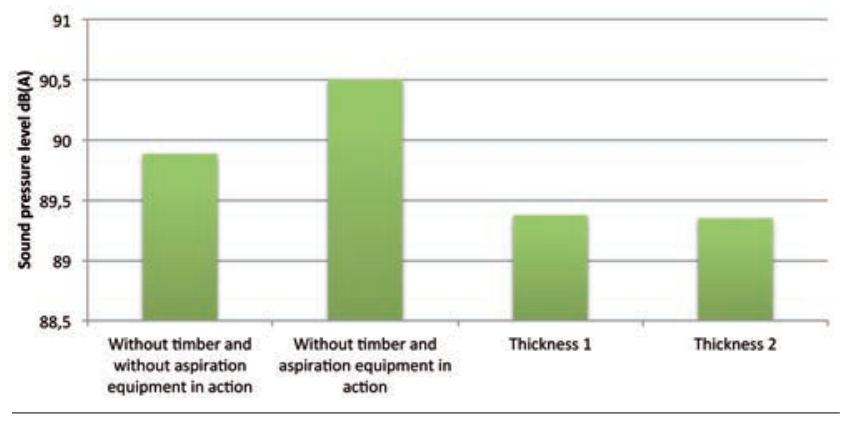

Figure 8. Graph of the sound pressure level trimmer.

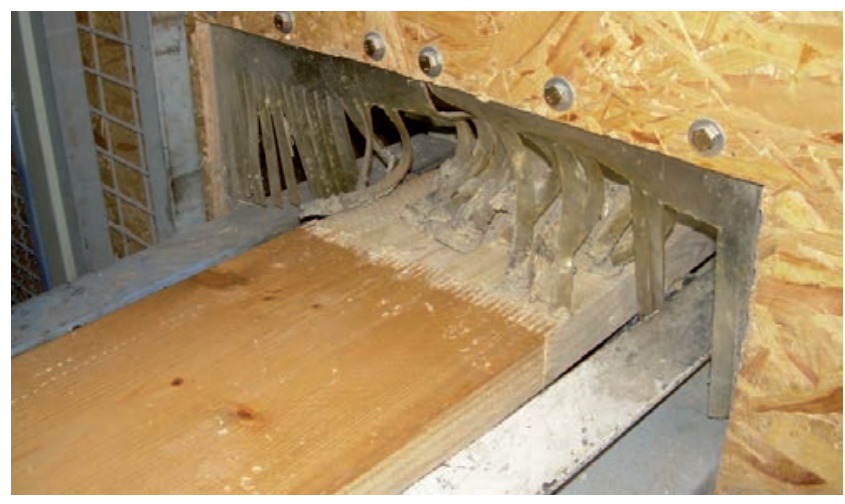

Figure 9. Joint system.

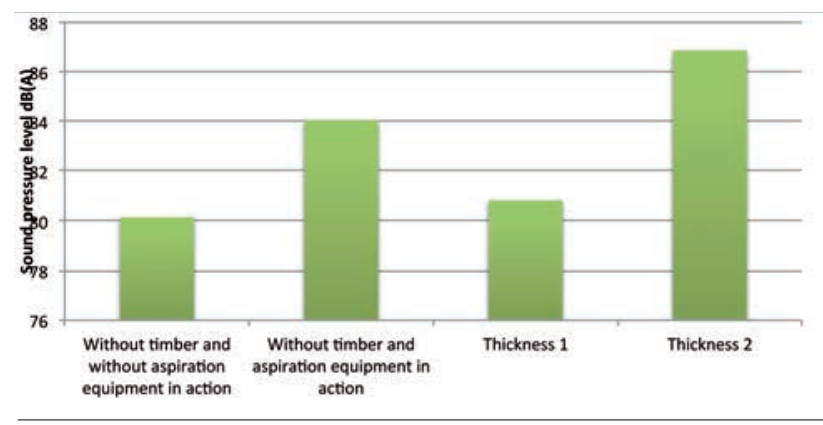

Figure 10. Graph of the sound pressure level of the splicing/splicer.

Table 1. Noise emission from machineries depending on wood thickness.

\begin{tabular}{|c|c|c|c|c|c|c|c|c|}
\hline \multirow[t]{3}{*}{ Values } & \multicolumn{8}{|c|}{ Machinery } \\
\hline & \multicolumn{2}{|c|}{ Trimmer } & \multicolumn{2}{|c|}{ Planer on four sides } & \multicolumn{2}{|c|}{ Splicer } & \multicolumn{2}{|c|}{ Profiler } \\
\hline & Thickness 1 & Thickness 2 & Thickness 1 & Thickness 2 & Thickness 1 & Thickness 2 & Thickness 1 & Thickness 2 \\
\hline Min & 79,9 & 80 & 88,3 & 88,2 & 77,6 & 85 & 85 & 84,4 \\
\hline Average & 91,5 & 92,7 & 90,9 & 90,1 & 88,7 & 92,3 & 97,5 & 94,9 \\
\hline Max & 96,1 & 97,2 & 93,4 & 92,7 & 96 & 100,2 & 104,3 & 105,9 \\
\hline
\end{tabular}


proofing of machinery. Existing legislation envisages that workers exposed to values of LEP, $8 \mathrm{~h}$ higher than $85 \mathrm{~dB}(\mathrm{~A})$ must wear adequate individual protection devices (i.p.d.) (antinoise protection, such as ear plugs, headphones or similar devices). In work areas with levels of LEP, $8 \mathrm{~h}$ in excess of $87 \mathrm{~dB}(\mathrm{~A})$, the employer must mark the perimeter clearly and provide signposting limiting access solely to authorized personnel who must wear individual protection devices. These devices must ensure that the level of risk is maintained within values equal to or lower than $90 \mathrm{~dB}(\mathrm{~A})$. The new directive (2003/10/EC) assumes that protectors are used always when noise level exceed $85 \mathrm{~dB}$. This study shows that this assumption is not always valid and thus efforts must be made to promote the use of hearing protectors. In risk assessment the protection efficiency of HPDs is taken into account. The protection efficiency is predictable only if the HPDs are properly fitted and users are motivated. There are several other factors such as cold/heat, comfort of HPDs, and variation of noise levels that affect the usage rates. The effect of these factors must be studied case by case. The usage of HPDs was at an adequate level in the tested sawmill. It is likely that the usage rate will increase due to growing risk awareness and the fact that young people are used to wearing protectors from the beginning. Hearing conservation precautions are progressing well in the enterprise included in this study. However, this progress cannot be generalized between all workers.

\section{References}

2003/10/EC, 2003. Council directive on the minimum health and safety requirements regarding to the exposure of workers to the risks arising from physical factors (noise). European Commission, Brussels, 6p.

Berger E.H., Franks J.R., Lindgren F. 1983. International review of field studies of hearing protector attenuation, inScientific Basis of Noise-Induced Hearing loss,Axelsson A., Borchgrevink H.,
Hamenik R.P., Hellstrom P., Hendersson D., Salvi R.J. eds. Thieme Medical Publ. p361-367.

Casali J.G., Park M.J. (1991). Real-Ear Attenuation under Laboratory and Industrial Test Conditions as Provided by Selected Hearing Protectors, InProceedings of the Human Factors Society 35th Annual meeting,Vol. 2, San Francisco, California, September 2-6, 1991. Pp 1110-1114.

Chang-Chun L., Pekkarinen J., Starck J. 1989. Application of the probe microphone method to measure attenuation of hearing protectors against high impulse sound levels,Appl. Acoustics27:13-25.

ComiteEuropeen de Normalisation (CEN) (2003). Hearing protectors Safety requirements and testing- part 2: Earplugs, (CEN Standard EN 352-2), Brussels: CEN pp15.

Foreshaw S., Cruchley J. 1981. Hearing protector problems in military operations. In:Personal hearing protection in industry,Alberti P., ed. New York: Raven Press: 387-402.

Nieminen 0., Starck J., Toppila E., Pekkarinen, J., Pyykko I. (2000). Protection efficiency of hearing protectors among workers in a paper mill. Transactions of the XXV Congress of the Scandinavian Oto-Laryngological Society, Olofsson J. Ed., DavesTryckeri, Bergen, Norway,Scand. J. Audiol.P 51-53.

Pekkarinen, J. 1987. Industrial impulse noise, crest factor and the effect of earmuffs.Am. Ind. Hyg, Assoc. J.48:10:861-866.

Pykko I., Koskimies K., Starck J., Pekkarinen J., Inaba R. 1989. Risk factors in the genesis of sensory neural hearing loss in Finnish forestry workers.Br. J. Ind. Med.46: 439-446.

Rantanen J., Kauppinen T., Toikkanen J., Kurppa K., Lehtinen, S., Leino T. (2001). Work and health country profiles: country profiles and national surveillance indicators in occupational health and safety, People and work, Research report 44.

Rotella A., Campurra G. 2008. Il rischio rumore negli ambienti di lavoro. IPSOA INDICITALIA.

TESTO UNICO - Decreto legislativo 9 aprile 2008, n. 81 "Attuazione dell'articolo 1 della legge 3 agosto 2007, n. 123, in materia di tutela della salute e della sicurezza nei luoghi di lavoro" e successive modifiche. 2008. 